\title{
EXCISÃO LAPAROSCÓPICA DE ÚRACO REMANESCENTE EM UM ADULTO
}

\section{LAPAROSCOPIC EXCISION OF THE URACHAL REMNANT IN AN ADULT}

\author{
Gustavo Lopes de Carvalho, TCBC-PE ${ }^{1}$; Frederico Guilherme de Paula Lopes Santos ${ }^{2}$; \\ Roberta de Castro Chaves Cabral ${ }^{2}$
}

\section{INTRODUÇÃO}

O úraco ou ligamento médio umbilical se estende do umbigo ao ápice da bexiga. É composto por um tecido fibromuscular que, mesmo no adulto, pode aparecer com um lúmen estreito tubular coberto por epitélio transicional modificado ou por mucosa de epitélio colunar semelhante ao do intestino. Embriologicamente, o úraco é derivado em parte do alantóide e em parte da porção ventral da cloaca, ocorrendo o seu fechamento, geralmente, em torno da $5^{\mathrm{a}}$ semana; no entanto, ocasionalmente, o mesmo pode permanecer pérvio. A persistência do úraco é achado infreqüente e tem importância clínica na presença de infecções, neoplasias ou dilatação cística ${ }^{1}$.

O objetivo do presente estudo é relatar um caso de excisão videolaparoscopia de úraco persistente e sintomático.

\section{RELATO DO CASO}

Paciente do sexo masculino, 25 anos, branco, apresentando eliminação intermitente de secreção fluida e fétida pelo umbigo há um ano. Relatava episódio de sangramento espontâneo, vermelho vivo, e eliminação de um coágulo pelo umbigo neste período.

Apresentou três episódios de fortes dores abdominais difusas nos últimos 12 anos, havendo nestas ocasiões necessidade de atendimento de emergência. Essas dores cessavam após medicação analgésica.

Ao exame físico pré-operatório apresentava apenas dor quando da palpação da região umbilical. Dentre os exames complementares solicitados, a ultra-sonografia abdominal detectou a presença de uma hérnia epigástrica, não evidenciando massas, coleções ou trajetos fistulosos umbilicais. A ressonância magnética da parede abdominal detectou trajeto fistuloso na região umbilical compatível com patência do úraco (Figura 1).

Realizou-se a videolaparoscopia pela técnica de três trocartes, sendo utilizado o orifício da hérnia epigástrica para a introdução do trocarte de $10 \mathrm{~mm}$. Após inspeção da cavidade com laparoscópio de $30^{\circ}$, foram introduzidos nos flancos dois trocartes de $5 \mathrm{~mm}$. O trajeto fistuloso do úraco, desde a região umbilical, foi ressecado com uso de tesoura ultrassônica (Figura 2A), sua base ligada com fio absorvível (vicryl 2-0) (Figura 2B), seccionada próximo à bexiga (Figura 2C), colocada na bolsa (Figura 2D), retirado da cavidade abdominal. A seguir foi realizada a correção da hérnia epigástrica.

O paciente recebeu alta no primeiro dia de pós-operatório.

\section{DISCUSSÃO}

Lesões uracais raramente apresentam manifestações clínicas em adultos, sendo mais freqüentes os problemas em crianças $^{1}$. A persistência do úraco é uma anomalia congênita pouco freqüente e vários tipos de remanescentes têm sido descritos: úraco patente, seios uracais, divertículos vesicouracais, seios alternantes e cistos uracais ${ }^{1,2}$. No úraco paten-

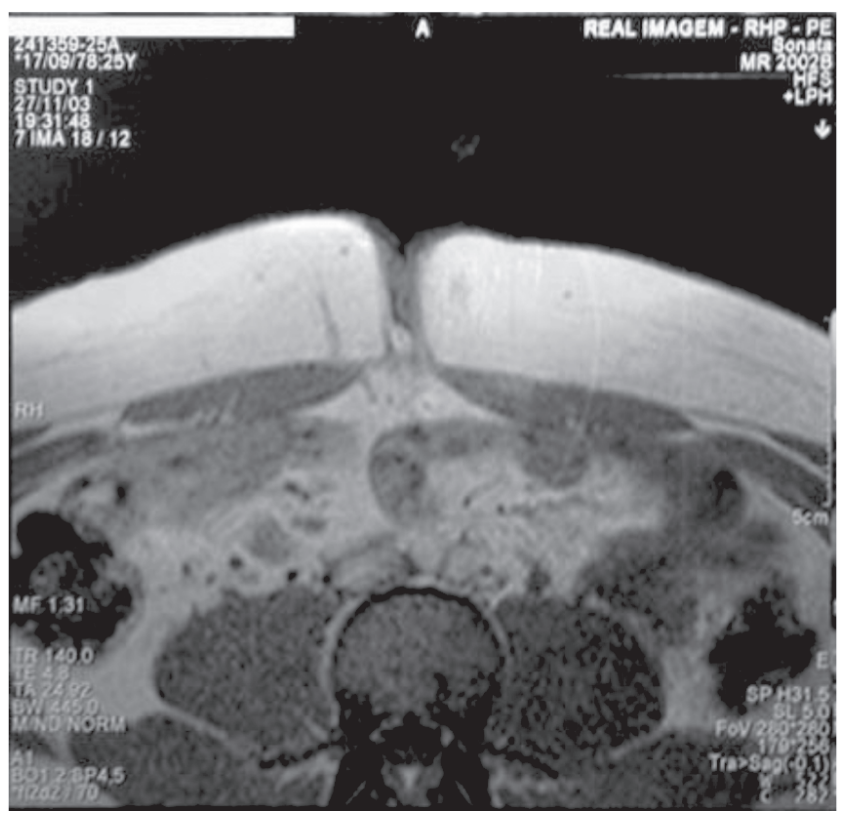

Figura 1 - Imagem de Ressonância Magnética da parede abdominal evidenciando trajeto fistuloso na região umbilical.

1. Mestre em Cirurgia pela UFPE; Doutor em Cirurgia pela UFPE; Membro Internacional do SAGES; Membro da SOBRACIL

2. Acadêmico do Curso de Medicina da UPE.

Recebido em 30/05/2005

Aceito para publicação em 01/07/2005

Conflito de interesses: Não há

Fonte de financiamento: Nenhuma

Trabalho realizado na Faculdade de Ciências Médicas - FCM / UPE e na Clínica Cirúrgica Videolaparoscópica Gustavo Carvalho. 

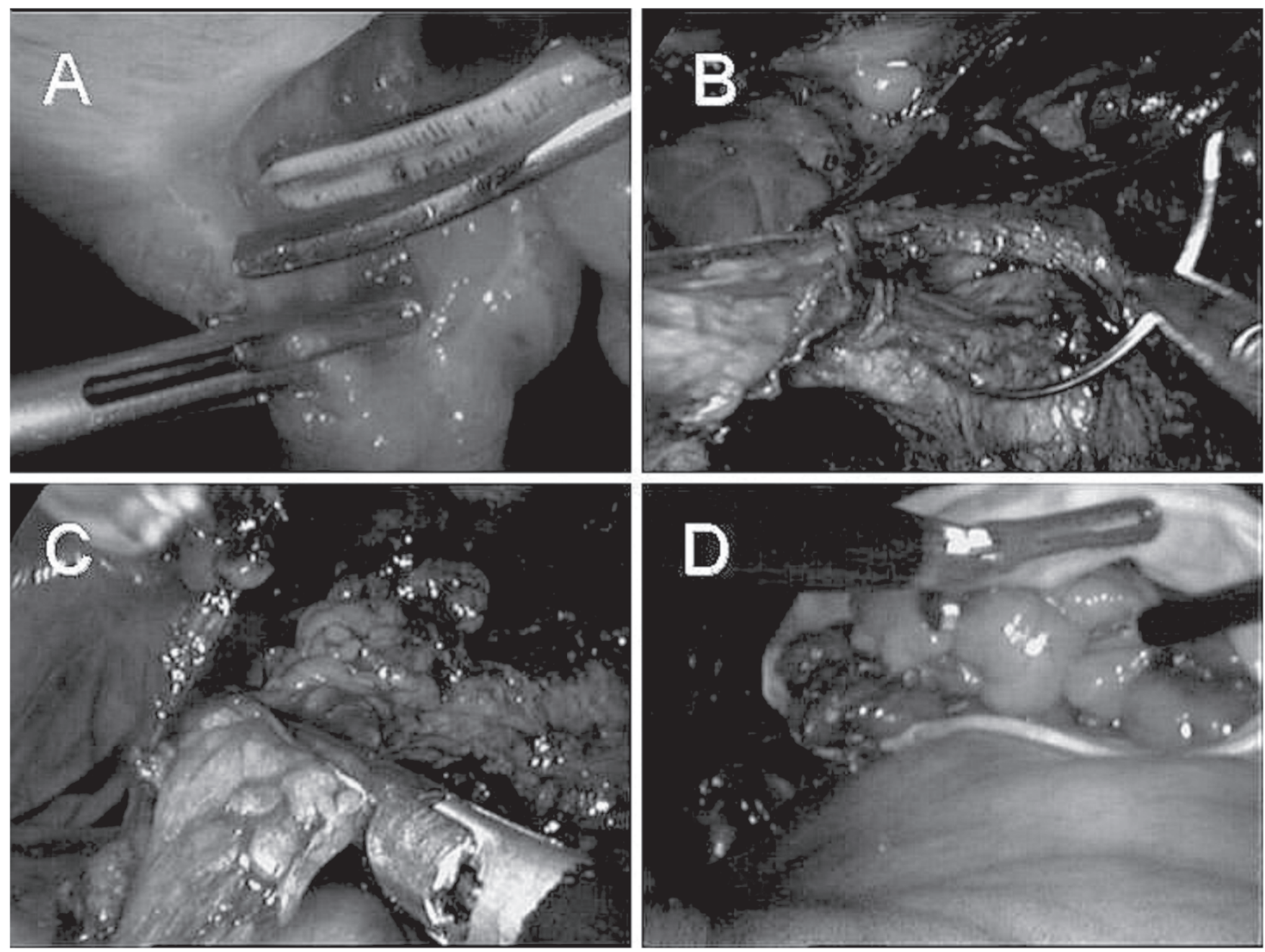

Figura 2 -Imagens do procedimento videolaparoscópico: $\boldsymbol{A}$-Início da ressecção do trajeto fistuloso peri-umbilical; $\boldsymbol{B}$ - Ligadura do úraco persistente próximo à bexiga; $\boldsymbol{C}$-Secção do úraco com tesoura ultrassônica próximo à bexiga; $\boldsymbol{D}$-Retirada do úraco remanescente em bolsa.

te, a estrutura uracal completa encontra-se intacta ${ }^{1}$, representando $15 \%$ das anormalidades do úraco ${ }^{3}$.

O diagnóstico de certeza das anormalidades uracais pode ser feito através de um bom exame físico associado a um estudo de imagem apropriado ${ }^{3}$. $\mathrm{O}$ diagnóstico pré-operatório da malformação uracal favorece a uma abordagem cirúrgica mais precisa. A ultra-sonografia tem se apresentado como o principal método diagnóstico nesse tipo de doença ${ }^{4}$. A tomografia computadorizada e a ressonância magnética permitem maior riqueza de detalhes e visualização de cistos pequenos e trajetos fistulosos, imperceptíveis à ultra-sonografia, como no caso em estudo.
Apesar de pouco freqüentes, as doenças causadas pelos remanescentes uracais não devem ser consideradas meras curiosidades médicas e as infecções desses remanescentes não devem ser esquecidas no diagnóstico diferencial de onfalite, dor abdominal aguda e infecções pélvicas ${ }^{4}$.

Apesar da excisão por cirurgia aberta ter representado o tratamento de escolha por muitos anos, a abordagem vídeolaparoscópica aparenta ser uma melhor alternativa devido à associação com menos dor pós-operatória, recuperação mais rápida, melhor resultado cosméti$\mathrm{co}^{2}$, além da praticidade, segurança e mínima invasividade da técnica ${ }^{5}$.

\footnotetext{
ABSTRACT

Abnormalities of the urachus in adults are uncommon. Urachal tract remnants, which abnormally remain patent, may be responsible for abdominal pain and infection. The persistence of the urachus can lead to several abnormalities; and the patent urachus is one of the less frequent. A 25-year-old man presented a fluid secretion from the umbilicus that bled once and had three previous episodes of abdominal pain. Magnetic Resonance Imaging revealed a patent urachus, which was confirmed by anatomopathological examination. The goal of this article is to report an urachal excision in a young adult with persistence of a patent urachus fully performed laparoscopically (Rev. Col. Bras. Cir. 2006; 33(6): 416-418).
} 


\section{REFERÊNCIAS}

1. Frangandreas G, Flaris N, Tsantilas D. Large serous urachal cyst in an adult. Hippokratia. 2002;6(4):167-70.

2. Yohannes P, Bruno T, Pathan M, Baltaro R. Laparoscopic radical excision of urachal sinus. J Endourol. 2003 Sep;17(7):475-9; discussion 479.

3. Cilento BG Jr, Bauer SB, Retik AB, Peters CA, Atala A. Urachal anomalies: defining the best diagnostic modality. Urology. 1998 Jul;52(1):120-2.

4. Favorito LA, Rachid Filho D, Gomes SR. Infected urachal cyst mimicking an acute abdomen. Braz J Urol. 2001;27(3):262-3.

5. Groot-Wassink T, Deo H, Charfare H, Foley R. Laparoscopic excision of the urachus. Surg Endosc. 2000 Jul;14(7):680-1. Epub 2000 May 22.
Como citar este artigo:

Carvalho GL, Santos FGP, Cabral RCC. Excisão laparoscópica de úraco remanescente em um adulto. Rev Col Bras Cir. [periódico na Internet] 2006 Nov-Dez;33(6). Disponível em URL: http:// www.scielo.br/rcbc

Endereço para correspondência:

Gustavo Carvalho

Avenida Domingos Ferreira 2766

51020-030 - Recife - PE

Tel: 5581 9971-9698 Fax: 5581 3325-3318

E-mail: gc@elogica.com.br./gc@superig.com.br 